\title{
Educational Leadership and Motivation in the School Unit
}

\author{
E. Lekka \\ Hellenic Open University \\ Vasiliki Brinia (Corresponding author) \\ Athens University of Economics and Business \\ Email: vbjournal@hotmail.com \\ P. Chatzipanagiotou \\ European University Cyprus
}

Received: February 02, 2016 Accepted: February 24, 2016 Published: April 08, 2016

doi:10.5296/jsr.v7i1.9251 URL: http://dx.doi.org/10.5296/jsr.v7i1.9251

\begin{abstract}
The purpose of this research is to demonstrate the significance of the teachers' motivation by the principal of their school and its correlation with the effectiveness of the school unit. The research was conducted in a sample of school principals with the method of the anonymous questionnaire. The sample was school principals whose schools are located in the Greek capital, Athens. The school principals have full awareness of the difficulties and the responsibilities that result from their multidimensional role in the Greek educational system. They believe, however, that they can achieve the goals of their school with a spirit of collaboration.
\end{abstract}

Keywords: Motivation, Effectiveness of management, Leadership, School management 


\section{MIN Macrothink}

\section{Introduction}

The majority of teachers should support the administration in its efforts to improve the effectiveness of the school unit. Communication between teachers and principals, incentives and encouragement for innovation and changes improve teachers' personal satisfaction and schools' effectiveness.

Encouraging and supervising teachers in times of crisis and change, taking responsibilities and assigning roles, increase the performance of the school and the quality of the educational process. According to Everard \& Morris (1999) maintaining maximum contact with the stakeholders, avoiding barriers and promoting programs in which all teachers can work together can help in order to reduce the negative consequences of conflict and can lead to the fulfillment of the educational objectives. Furthermore, motivating teachers to participate in decision making in all aspects of the school leads to a more efficient administration.

Leadership, according to Pasiardis (2004), is beyond administration and management. The principal must be transformed from a manager to a leader who will be flexible and will promote innovation in order to create "internal" educational policies and set high goals for its school (Saitis, 2005).

\section{Theoretical Part}

\subsection{Motivation}

Human Resource Management is "the set of activities aimed at achieving the organization's business objectives generally through the use of equipment and human resources" (Papalexandri \& Bourandas, 2003). The internal process which is connected with the job satisfaction through the achievement of the objectives that are set by the organization is called motivation (Bourandas, 2002).

It is difficult to give a specific and unique definition for motivation. According to Atkinson (1964) motivation is "the inner strength that guides and directs human behavior and affects the vigor and persistence in an act". Machr \& Braskamp (1986) present motivation as a process related to the tendency of people to use their own resources (time, energy, talent) according to their own desires. Everard \& Morris (1999) define motivation as "achieving results through people "or" to get the best out of people". Berelson \& Steiner (1967) define motivation as "an internal state that activates, drives and directs people's behavior toward their goals".

In Greece it is essential to "unlock the potential of people", because the human resources are the "most important asset" in an organization (Brinia, 2008). The development of human resources plays an important role in achieving the organization's objectives and is also applicable to educational organizations. Developing the human resources in an educational unit "is a responsibility of the school towards teachers, students, parents, the state and society in general" (Brinia, 2008). 


\subsection{Theories in Motivation}

Theories of motivation are associated with Management and in particular with the operation of Administration, whose main purpose is the achievement of the organization's objectives by influencing and directing the behavior of its personnel. According to Pasiardis (2004), "the organizations are trying to satisfy their needs but also satisfy the needs of their employees". The motivation theories are essential tools in the hands of the leader both in the private and in the public sector. In modern Management these theories play an important role and can be divided into three categories with regards to their content (Bourandas 2002; Bourandas \& Papalexandri, 1998):

- Theories that try to present the content of motivation and emphasize the needs and incentives that make people work.

- Theories that try to identify the motivation process and in particular the initial objectives which incite people.

- Theories that investigate the influence of past behaviors in future results.

In modern educational organizations, there should be means and activities in order to improve the working conditions and the organization culture while they will offer satisfaction to the employees. The work should be interesting to the employee and it should provide a sense of responsibility and safety. Additionally, it should promote initiatives and opportunities for growth, encourage innovative actions in the pedagogical and teaching work and create conditions for professional and personal development. The positive climate and school relations (especially the relation between principals and teachers) can help the teacher to derive satisfaction from work. Consequently, teachers can thrive and work efficiently if they are personally or professionally motivated (Pasiardis 2004).

\subsection{Effective School Management}

The effectiveness of the school is an extremely complicated issue, which is related to the specific characteristics of the educational units in relation to other organizations. "The concept of effectiveness is generally associated with achieving goals with the least possible waste of resources and it is a key element for the creation and the survival of organizations" (Papaloi, 2012).

The effective operation and management of the educational unit is directly linked with the ability of the principal-leader to provide opportunities for professional development of teachers while enhancing the current knowledge and skills. The principal should promote cooperation, the acquisition of educational experiences, respect and trust among members of the educational community, in order to optimize the effectiveness at the individual level and at the school level. According to Saitis (2008), the school administration is effective when the expectations of the principal/leader, the employees and the general goals of the educational unit converge. The most effective managers are those who are actively involved in school life, they are innovators and lifelong learners, while they have high expectations firstly of themselves and secondly from the others (Pasiardis, 2004). 
The importance of motivation is related to the employees' satisfaction, because it increases the efficiency of the management's objectives. According to Iordanidis (2005), the most important aspects of the role of a principal are: a) creating vision, b) motivating the staff, c) team management and d) creating the right climate. Saito (2005) and Hatzipanagiotou (2003), refer to the following administrative activities of management of schools: a) motivating teachers, b) managing conflicts c) ensuring communication, d) cultivating favorable organizational culture and climate and e) caring for the development of teachers.

In administrative relations and during the implementation of any technique three basic rules should apply (Everard \& Morris, 1999):

1. Using the "promoters", which are the need of people for achievement, recognition, responsibility, advancement, interest and job prospect. When the teacher has a say in decisions which affect him/her, it helps in meeting most of these needs.

2. Taking into account the fact that the relative intensity of the psychological needs vary greatly from period to period.

3. Adapting the managerial behavior to the individuals and the circumstances. Despite people's unwillingness the principal should not resign from the effort. Furthermore, the principal should propose alternatives and achieve the goal with the right approach.

\section{Research Part}

\subsection{Methodology}

The purpose of the research is the collection and evaluation of data in order to explore the attitudes, opinions and perceptions of school principals of secondary vocational education on the importance of motivation and its contribution to the effectiveness of the provided educational work.

The quantitative approach was selected. In quantitative methods which are applied to large-scale studies, conclusions are easily measurable. The questionnaire was chosen as the data collection tool. The research process is based on the experience of principals in achieving the goals of the school.

The questionnaire helps in collecting reliable information and data because it is anonymous and can be filled without the presence of the researcher. It is preferred because it can result in conclusions quickly and easily (Karageorgos, 2002). Data processing can be performed quickly and reliably using statistical programs. The questionnaire of this research consists of two parts. The first part contains questions in the general - demographic characteristics of the participants. The second part consists of closed questions which can be answered using the Likert five point rating scale.

The method of convenient sampling was chosen for selecting the sample. The questionnaires were distributed to 50 school principals of vocational-technical and secondary education, in the Greek capital, Athens. 40 principals returned the questionnaires. The distribution and collection of the questionnaires took place in March-April of 2015. 
After the collection of the questionnaires, the variables were codified and the data was edited with the statistical program SPSS STATISTICS 20.0. (Statistical Package for the Social Sciences).

\subsection{Results}

The answers given by the respondents showed that principals encourage greatly $($ mean $=4.40$ ) students and teachers during the educational process and they constantly motivate them to reach new higher goals.

$55 \%$ of principals always and $42.5 \%$ often rewards the teachers publically for their initiatives (mean 4.53). Furthermore, particularly common is for principals to promote new methods of teaching and educational innovations in their school (mean $=4.05)$, while frequent is the encouragement or incitement of teachers in adopting interdisciplinary approach to curriculum (average value $=3.85$ ). Finally less frequent seems to be the support in teachers' initiative to co-teaching with colleagues (mean $=3.46)$, with the majority of respondents $(45 \%)$ to support it only sometimes.

The vast majority of respondents believes (90\%) that new faculty members need their support for the smooth adjustment and integration in school. In addition, a significant proportion of the sample stated that they feel much $(42.5 \%)$ or very much $(30 \%)$ the need for training in order to be able to contribute effectively to the integration of new members into the group of teachers.

The satisfaction of the emotional needs of teachers strongly affects the effectiveness of the operation of the school according to the answers of the respondents (mean $=4.40$ ).

On the communication between teachers and principals, $95 \%$ of the participants stated that in the beginning and during the school year they have private meetings with teachers and in order to exchange views on issues related not only to the operation of the school but also to the expectations and personal needs. $65 \%$ of respondents said that the meetings take place outside of the school environment. Finally almost all respondents $(97.5 \%)$ said they had a private meeting with each teacher to achieve the optimal allocation of responsibilities from the Teachers' Association, before the assignment of courses and tasks. Meetings which took place prior to decision making were very important (mean $=4.33$ ), as $55 \%$ of the sample responded that they were helpful and 37.5 that they were very helpful.

Regarding the teachers' need for training and professional development, $65 \%$ of the principals responded that they share it very much and $35 \%$ very. The respondents seem to help in meeting these needs primarily by facilitating involvement in training programs (mean $=4.40)$, and by providing adequate information from the school (mean $=4.33)$. Additionally, principals use the skills and competencies of teachers (mean $=4.10)$ and internal training $($ mean $=4.00)$.

The expectation for reward comes from the recognition of the work of teachers by school principals $($ mean $=4.31)$, followed by students $($ mean $=4.15)$, their peers $($ mean $=3.92)$ and finally parents $($ mean $=3.82)$. 


\section{Macrothink}

The majority of the sample (55\%) believes very much and $37.5 \%$ much, that the principal is responsible for the formation of a positive climate in the school.

Finally respondents were asked how easy they find it to motivate and encourage other people The answers were grouped based on the degree of difficulty. The majority of the sample (40\%) said that it is difficult or that it is not easy to provide incentives to encourage other people, but it is manageable. Also, $7.5 \%$ report that it is easy to some extent, under conditions. Only $5 \%$ think that it is quite easy, while $12.5 \%$ think it is very or fairly difficult. According to some respondents, incentives and motivation are easy when there is cooperation rather than competitiveness, or when there is training and scientific support.

\subsection{Conclusions}

The management of human resources of an educational unit is a key element of effective management. Managing human resources is usually investigated in businesses and organizations in the private sector. However, the principles of management are applicable in educational organizations whether they are in private or public sector, with the appropriate adaptations.

In Greece, the theories about human resources management and the need to motivate employees are mainly applied in the last decades in the private sector. The concepts of the management of human resources and encouragement and motivation of staff have begun to interest and leaders of educational institutions.

Schools produce work which differs from that of other organizations. In Greek literature there is limited research evidence on the issue of motivation of teachers by manager-leader of the school. The findings of this research experience can help teachers and principals to upgrade their role in the school, with cooperation and understanding of the problems, efficient operation of the school, personal and professional development of teachers and education of high quality.

This research effort is aimed at raising awareness of teachers and their release in order to be able to express their needs as people and workers in a sensitive and with many peculiarities space. From the perspective of managers believe that there will be speculation and meet the needs of teachers in their schools. Through this research effort was made to demonstrate the need for employee satisfaction-but teachers from their jobs given by the directors optics. Their motivating the Director-democratic leader, anthropocentric orientation make substantial shareholders of the educational process all teachers and lead to the effectiveness of the educational and pedagogical work.

According to other participants incentives and motivation are difficult due to the lack of supportive staff. However, by knowing the philosophy of each colleague, cooperation, continuous effort, hard work, positive energy, knowledge, perseverance, patience, less bureaucracy, more freedom and interest in the professional life the obstacles can be overtaken. According to other participant, the Ministry of Education should upgrade the training and administrative support for schools in order to provide more incentives. 


\section{Macrothink}

This paper is part of Ms. E. Lekka' dissertation for the Hellenic Open University, submitted in September 2015. A' Supervisor P. Chatzipanagiotou, B' Supervisor V. Brinia

\section{References}

$\underline{\text { English }}$

Atkinson, J.W. (1964). Introduction to Motivation. Princeton NJ: Van Norstand.

Berelson, B., \& Steiner, G. A. (1967). Human behavior. Harcourt, Brace and World.

Maehr, M. L., \& Braskamp, L. A. (1986). The motivation factor: A theory of personal investment. Lexington Books/DC Heath and Com.

\section{Greek}

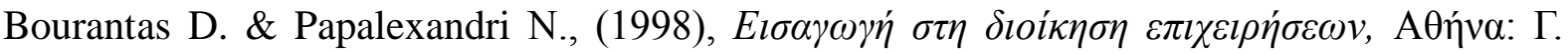
M $\pi \dot{v}$ ov.

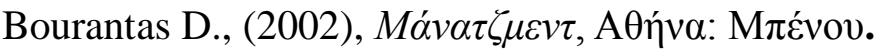

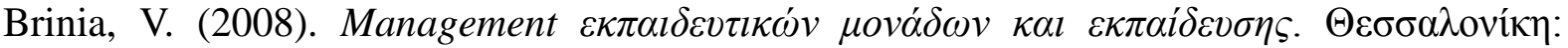

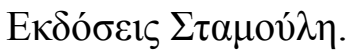

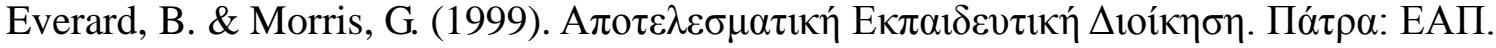

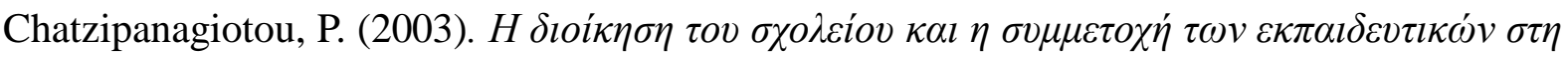

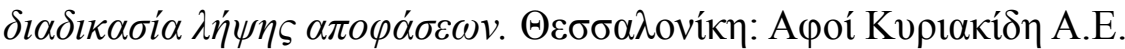

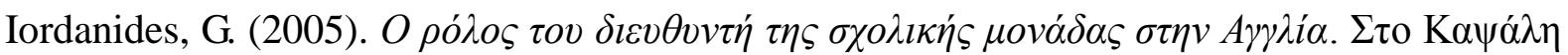

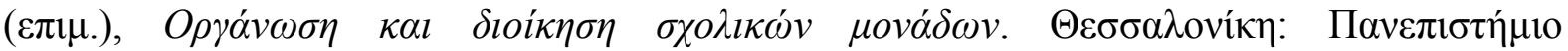

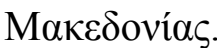

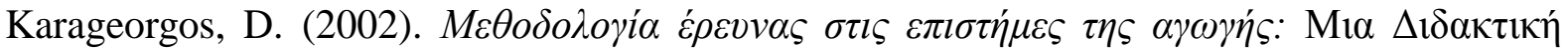
$\pi \rho о \sigma \varepsilon ́ \gamma \gamma 1 \sigma \eta$. А $\theta \eta ́ v \alpha: \Sigma \alpha \beta \beta \alpha ́ \lambda \alpha \varsigma$.

Maehr, M.L. \& Braskamp, L.A., (1986). The motivation factor a theory of personal investment. Lexighton Books.

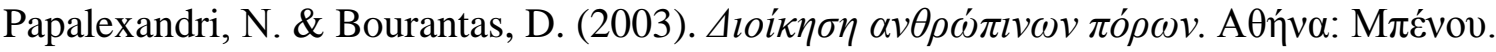

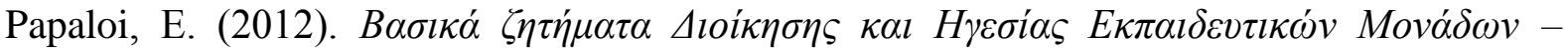

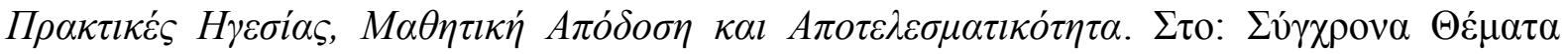

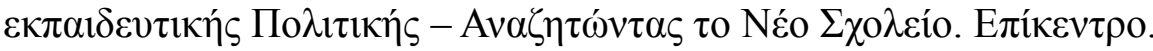

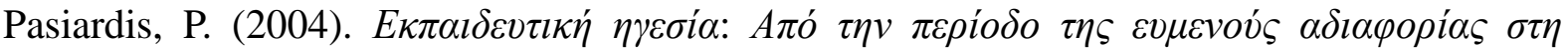

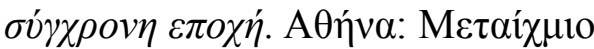




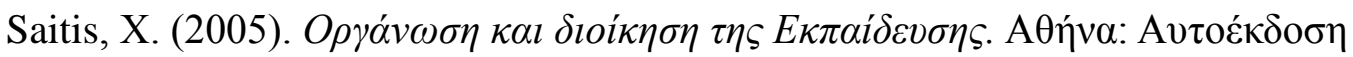

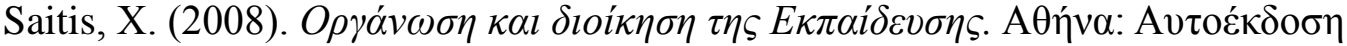

